\title{
Professionals' Perceptions on Construction Progress Measurement Methods Used in Ghana
}

\author{
James Cofie Danku1, Kofi Agyekum¹, Francis Terkpertey Asare² \\ ${ }^{1}$ Department of Construction Technology and Management, Kwame Nkrumah University of Science and Technology, Kumasi, \\ Ghana \\ ${ }^{2}$ GCB Bank, Accra, Ghana \\ Email: jmcdanku@yahoo.com
}

How to cite this paper: Danku, J.C., Agyekum, K. and Asare, F.T. (2020) Professionals' Perceptions on Construction Progress Measurement Methods Used in Ghana. World Journal of Engineering and Technology, 8, 145-158.

https://doi.org/10.4236/wjet.2020.82012

Received: February 8, 2020

Accepted: March 21, 2020

Published: March 24, 2020

Copyright $\odot 2020$ by author(s) and Scientific Research Publishing Inc. This work is licensed under the Creative Commons Attribution International License (CC BY 4.0).

http://creativecommons.org/licenses/by/4.0/

\begin{abstract}
Progress measurement is cardinal for effective project delivery. It assesses the physical amount of completed work within budgeted cost and manpower performance at a specified stage of the project. Effective progress measurement facilitates progress monitoring, an inevitability for identifying early warning signs and confirmation of structured work proceeding. Different progress measuring methods are available and used for construction projects. They range from the traditional to the contemporary ones like three-dimensional and four-dimensional models. This paper examines current progress measurement methods used in the Ghanaian construction industry. Eight commonly employed methods were identified from the literature and rated by sixty-two construction professionals, practicing with tier one construction firms and construction consultancy services. Relative Important Index ranking and Mann-Whitney $U$ test statistics were used to rank and check the consistency of survey responses. Cost Ratio ranked the highest, followed by Supervisor's Opinion and Units Completed. The fourth-ranked method was Time Ratio, then Incremental Milestone before Start-Finish. Weighted/Equivalent Units was at the penultimate with Earned Value Analysis ranked the lowest. The study will not only underscore the relevance of the current project progress measurement practices and provoke prolific debates on their merits, but will also serve as a precursor for critical evaluation of the methods with the view to identifying barriers militating against realistic progress assessment of construction works.
\end{abstract}

\section{Keywords}

Construction Progress Measurement Methods, Construction Professionals, Tier One Construction Companies, Ghana 


\section{Research Background}

\subsection{Introduction}

The proper focus and speed of construction cannot be economically attained by compulsion, but require careful and adequate planning and control. Under the unsteady, unpredictable and highly competitive construction business environment, progress and performance measurement are very critical for all categories of construction organizations, including clients, architects, quantity surveyors, engineering and contractors [1]. Assessment of the status of actual work completed at a designated phase against predetermined performance criteria (work quantity, budget and time) can serve as a medium for early identification and isolation of disparities in the tasks for corrective attention. Aside from highlighting current project performance, possible risk factors can also be forecast consequent to project progress measurement. Effective project measurement thus culminates into project success, if properly managed. Progress measurements are based on cost engineering and scheduling planning [2] [3] [4]. Typical construction progress measurement techniques will be sourced from literature and tested on professionals in tier one construction companies and consultancy services, using the survey strategy. The aim is to identify and rank the common progress measurement techniques, based on their frequency of application on construction projects. This will accentuate the current progress measurement practices and generate deliberations on their qualities and advantages. Most frequently employed methods can be scrutinized just as the least ones also interrogated for possible redress.

\subsection{Construction Project Progress Measurement}

One critical job specification of the project manager is to monitor and track work progress against the planned targeted schedule within accepted scope and cost. Effective project progress monitoring should identify early warning signs and also confirm whether the work is proceeding in a considered manner to avoid incessant pressure at the eleventh hour. Progress measurement is a critical component of successful project control in the project delivery caboodle. It is highly unlikely that a project will conform to plan, and all schedules during the construction phase, so the project manager must recognize this and be in a constant reactive mode to realign it back on track. Consequently, for any construction project to be delivered on time, within budget and at a specified quality, accurate progress measurement is crucial. Progress, according to Jung and Kang [5], can be defined as the assessment of actual work executed within a scheduled time and budgeted cost. Construction progress, as stated in AACE [6], is the overall physical percentage of completed work, cost performance and manpower performance at a specified period of the project. Thus, progress measurement can be considered as a method by which the defined scope of work can be quantified, such that each element can later be measured and aggregated with other elements to provide a measure of how far the project has progressed. In essence, 
progress measurement is the process by which the status of completion of a project at any defined stage can be quantified against a target work, its budget and time allocated. This subsequently will serve as a catalyst to forecast risks and postulate early corrective action through project monitoring with the overall fulfillment of project control, cost engineering and other performance indicators [7] [8].

There are several conventional and other emerging contemporary methods of measuring the progress of construction projects. According to Rahimian et al. [9], the majority of construction measuring techniques are conducted by the traditional approach. Predicated mainly on computer-assisted tool formats of 2-dimensional diagrams (bar charts, critical path network, photos, reports, etc.), the conventional methods broadly employ a percentage of completed work, milestones within the tasks and time-tracking as cardinal axes of measuring progress. The project schedule is used to track and record the completed percentage of work executed. Simple as this may appear, the method's assumption that work executed is proportional to the time elapsed can be erroneous and unreliable. Milestones segment the project into deliverables or deadlines which are assessed against baseline schedule dates to measure the project progress. Any project that entails a measure of man-hours expended on tasks before being regarded as wholly complete, falls under the time-tracking technique. The conglomeration of the traditional progress measurement methods presented by such authors as Garold [3], Amos [10], CII [11], Fleming and Koppelman [12], Mubarak (2010) [13] and Thomas and Mathews [14] can be summed up as Units Completed, Cost Ratio, Time Ratio and Start-Finish. The rest include Supervisor's Opinion, Incremental Milestone, Weighted or Equivalent Units and Earned value Analysis. These methods will be briefly discussed subsequently. It is noteworthy that these project measurement methods are not objective enough, lending themselves to individual influences, judgement, ability and experiences [15] [16]. Besides, apart from the Earned Value Analysis, none of the other systems integrated the three key project progress performance elements of cost, time and quantity of work done (work scope).

Contemporary progress measuring techniques use three-dimensional and four-dimensional (3D/4D) models and rely on Barcodes, Laser Detection and Ranging (LADAR), Video and Audio Technologies, Radio Frequency Identification (RFID) and Global Positioning System (GPS) for automatic data collection and visualization and real-time presentation of results. Golparvar-Fard et al. [7], Zhang et al. [8], Rahimian et al. [9], Chau et al. [17], El-Omari and Moselhi [18] and Navon [19] are some of the proponents of (3D/4D) computer augmented reality model for automating the progress measurement process. $3 \mathrm{D} / 4 / \mathrm{D}$ augmented progress measurement models have not been considered further in this paper. They are emerging techniques that require education and apposite understanding for successful implementation. Systems such as digital imaging and computer vision, are predicated on prerequisite information technology infrastructure. 
The eight traditional methods of measuring work progress are discussed below.

\subsubsection{Units Completed}

This progress measurement method is normally used for work packages whose scope can further be segregated into fairly standardized units of work such that each unit requires roughly the same level of effort to complete. Suited for repetitive tasks where each actual compact of iteration can easily be measured against the planned [4] [20]. It is a simple method that lends itself to objective tracking of tasks but is quantity bias to the neglect of time and cost.

\subsubsection{Start-Finish Method}

The emphasis of this method is on the commencing and ending points of the tasks with no consideration of the intermediate activities. It is best adaptable to small tasks with short durations. The construction manager or coordinator may assign two or three levels for the activity or work sections or the entire project. Not started will be $0 \%$, progressing but not completed (an arbitrary amount) says $45 \%$ or $60 \%$ and completed will be $100 \%$. Alternatively, the $0 / 100 \%$ (start/finish) could be applied to tasks of very high value, 20/80 for high-value tasks and 50/50 for very short tasks [4] [20]. This method can be applied easily to the whole project progress measurement but it could be subjective. It is simple at the activity level but experience and judgment will be required to apply it to the entire project.

\subsubsection{Supervisor's Opinion}

This is the most biased method which is mostly used where no other method will be appropriate to be applied. The supervisor simply makes a judgement on the percentage of work completed. As a subjective approach, it should be reserved for only minor tasks where other options cannot be used. This method depends solely on the experience and opinion of the supervisor [10] [13] [21]. It is quick though and easy to use, however applicable to relatively minor tasks which must be used only as the last resort.

\subsubsection{Cost Ratio}

A preferred method for project management contracts, the Cost is usually applicable to construction activities which do not have discrete deliverables and tend to occur over a relatively long period of time [10] [11] [13]. The percentage completion is determined by the ratio of the actual cost to the estimated cost at completion (or budgeted cost to date to projected baseline cost budget). The Cost Ratio is an objective technique which is simple and quick, applicable to work sections or the entire project. Not a precise method because it is limited to only one project element (cost).

\subsubsection{Time Ratio}

Another favorite method for project management contracts, the Time Ratio is also apposite for tasks such as contract administration and project management. It is estimated on the basis of time (work-hours) accomplished on a project ra- 
ther than on the actual production [10] [11] [13]. The percentage completed is calculated on the proportion of actual time elapsed to the estimated time of completion. The Time Ratio is simple and quick but not detailed or accurate because the cost and scope of work (quantity) are not factored in.

\subsubsection{Incremental Milestone}

Applicable to projects which involve subtasks or steps which must be carried out in sequence so that the completion of incremental tasks can be observed. Each stage or step of a given project is assigned a "weight" that is approximately equivalent to its percentage share of effort in the task of the project. Milestones can be considered as an important means of tracking progress as they are substantially tied to activities on the schedule. This method seems simple but highly dependent on the experience of the supervisor who assigns or estimates the weights or milestones [22] [23].

\subsubsection{Weighted or Equivalent Units}

This method is a combination of units completed and incremental milestone. It is used for projects of relatively long durations, when the work package scopes, include multiple subtasks of non-standardized units of work that overlap such that the other methods cannot work well. The cardinal point here is to accumulate the weighted value which is eventually denominated into the value of the units of specific tasks. Ideal for activity level progress measurement due to its level of objectivity, but relies on past experience of the project manager to assign weights [4] [10] [13].

\subsubsection{Earned Value Analysis}

Earned Value Analysis is a system employed to determine the actual or physical progress of the project and it incorporates scope, time and cost [24] [25] [26]. It requires regular and systematic cost and time documentation in order to constructively compare the budgeted cost of work assigned to the actual cost of work performed for a work breakdown structure component [27] [28]. Thus, it allows one to establish what has been completed against what has been planned and then uses the level of performance/progress achieved to provide a more realistic assessment of where a project is heading in terms of cost and schedule [3] [29]. The project will "earn value" when scheduled activities are completed, with correlated costs within the budgeted [5] [30]. The main benefits of Earned Value Analysis are that it objectively measures project progress and offers prior indicators of performance issues to improve predictability.

\section{Research Method}

The professionals' assessment of their familiarity and application of construction project progress measurement techniques in Ghana was undertaken through literature review and survey strategy. Data collected were analyzed quantitatively, using descriptive and inferential statistics [31] [32]. The common methods of construction project progress measurement were identified from relevant litera- 
ture and presented to construction professionals working with construction and consultancy firms to rate. Adopting the purposive sampling technique, sets of questionnaires were self-administered to tier-one $(D 1 K 1)$ Building Construction and Quantity Surveying Consultancy firms in the Greater Accra region of Ghana. This region is selected for the study not merely because of the location of the capital town, but a large proportion of construction firms (over 50\% of tier-one building construction and three-quarters of Quantity Surveying firms) are found in it (Association of Building and Civil Engineering Contractors of Ghana and Ghana Institution of Surveys records). The decision to limit the opinions of consultants to only Quantity Surveyors was based on a preliminary survey which revealed that over 90\% of Architects and Engineers derive their progress information from the Quantity Surveyors' interim certificates. A structured questionnaire was used as a research tool [33] to solicit information from construction professionals. A central motif of the questionnaire entreated the contractors and consultants to rate the eight traditional methods of progress measurement systems. The respondents were expected to rate these factors according to their frequency of application on a five-point Likert scale, viz: 1-Never, 2-Seldom, 3-Sometimes, 4-Often and 5-Almost Always [34]. Lists of tier one ( $D 1 K 1)$ contractors obtained from Association of Building and Civil Engineering Contractors of Ghana (ABCECG) and Quantity Surveyors from the Ghana Institution of Surveyors (GhIS) secretariats gave the numbers of firms practicing in the Greater Accra Region as 43 and 28 respectively. Employing the census technique, due to the small populations, questionnaires were distributed to professionals in construction firms responsible for project progress management. Taking a cue from Antwi [35] and Ahadzie [36] on their warning on low response rates to questionnaires in Ghana, a personal distribution and retrieval system was pursued. Company head office locations and contact addresses obtained from directories at ABCECG and GhIS secretariats facilitated this. Three months was used to retrieve the questionnaire because of multiple visitations to some offices.

A total of sixty-two sets of questionnaires (87\%), comprising 36 (84\%) Contractors and 26 (93\%) Consultants, were retrieved and used in the analysis. Table 1 shows the demography of the respondents. Majority of respondents (97\%) are either at management level or senior staff. Ninety-eight percent of the 62 respondents have been working in the industry for at least six years. Regarding the level of knowledge of construction practitioners in the Construction Project Progress Measurement, $43.5 \%$ have adequate enlightenment and 51.6\% advanced understanding of the system. It can, therefore, be ultimately asserted that the chosen groups of respondents have the necessary experience and understanding of the system to contribute valuable data for this study. The data collected were analyzed by descriptive statistics of Relative Important Index (RII) and non-parametric Mann-Whitney U-test [37] [38]. The former ranks the means of the rated factors (on the Likert scale) while the latter compares the differences 
Table 1. Demography of respondents.

\begin{tabular}{|c|c|c|c|}
\hline Variable & Characteristics & Frequency & Percentage \\
\hline \multirow{3}{*}{ Firm } & Construction Firms & 36 & 58.1 \\
\hline & Consultancy Services & 26 & 41.9 \\
\hline & Total & 62 & 100.0 \\
\hline \multirow{4}{*}{ Position in Firm } & Senior staff & 33 & 53.2 \\
\hline & Junior staff & 2 & 3.2 \\
\hline & Management & 27 & 43.5 \\
\hline & Total & 62 & 100.0 \\
\hline \multirow{6}{*}{ Working Experience } & $1-5$ years & 1 & 1.6 \\
\hline & $6-10$ years & 13 & 21.0 \\
\hline & $11-15$ years & 12 & 19.4 \\
\hline & $16-20$ years & 21 & 33.9 \\
\hline & Above 20 years & 15 & 24.2 \\
\hline & Total & 62 & 100.0 \\
\hline \multirow{4}{*}{$\begin{array}{c}\text { Knowledge in Construction Project } \\
\text { Progress Measurement }\end{array}$} & Intermediate & 3 & 4.8 \\
\hline & Adequate & 27 & 43.5 \\
\hline & Advanced & 32 & 51.6 \\
\hline & Total & 62 & 100.0 \\
\hline
\end{tabular}

in the averages of the ranks across the two groups (contractors and consultants). The non-parametric or distribution-free alternative is used because no assumptions about the parameters (such as shape and variance) of the population are made, instead, the mean ranks are used.

\section{Results}

The eight (8) common methods of construction progress measurement which were identified from the literature include Units Completed, Cost Ratio, Time Ratio and Start-Finish. The rest are Supervisor's opinion, Incremental Milestone, Weighted or Equivalent Units and Earned Value Analysis. These were tested on construction professionals to determine their familiarity and level of application. The Relative Importance Index (RII) was calculated for the eight methods of project progress measurement based on their mean scores. The rankings are presented in Table 2 and indicate the level of application of the existing methods among practitioners. The highest-ranked method is the Cost Ratio with a mean of 4.84 and corresponding RII of 96.8. This is closely followed by Supervisor's Opinion method with mean and RII of 4.52 and 90.3 respectively. The Units Completed, Time Ratio and Incremental Milestone, followed in that order. The Start-Finish and Weighted/Equivalent Units, having RII of 56.1 and 32.9, were rated low. Earned Value Analysis is ranked last with a mean score of 1.60 and RII of 31.9. 
Table 2. Construction progress measurement methods currently in use in Ghana.

\begin{tabular}{ccccccc}
\hline Method & N & Sum & Mean & Standard Deviation & RII & Ranking \\
\hline Cost Ratio & 62 & 300 & 4.84 & 0.549 & 96.8 & 1 \\
Supervisor's Opinion & 62 & 280 & 4.52 & 0.954 & 90.3 & 2 \\
Units Completed & 62 & 246 & 3.97 & 0.829 & 79.4 & 3 \\
Time Ratio & 62 & 221 & 3.56 & 1.140 & 71.3 & 4 \\
Incremental Milestone & 62 & 198 & 3.19 & 1.006 & 63.9 & 5 \\
Start-Finish & 62 & 174 & 2.81 & 1.353 & 56.1 & 6 \\
Weighted/Equivalent Units & 62 & 102 & 1.65 & 0.630 & 32.9 & 7 \\
Eared Value Analysis & 62 & 99 & 1.60 & 0.858 & 31.9 & 8 \\
\hline
\end{tabular}

Mann-Whitney $U$-test, a non-parametric alternative to the t-test, was used to compare differences between the two independent data sets (Contractors and Consultants) for the given dependent variable (e.g. Cost Ratio or Units Completed). As the data were skewed and participants' numbers were small, the choice of this technique, which requires no assumptions about the parameters of the population, is appropriate [31]. In this test, the results were ranked as belonging to one series of measurements based on the mean of the ranking. Table 3 and Table 4 provide information about the convergence of these two variables (Contractors and Consultants) in relation to the project progress measurement methods. These tables were derived from SPSS (Statistical package for social scientists, V 20) output. From Table 3, it can be seen that there is virtually no difference in the mean ranks of the contractors (31.86) and Consultants (31) with respect to Cost Ratio. It shows that both groups rated Cost Ratio almost equally. The mean ranks of the Contractors and Consultants for the Start-Finish method are 28.74 and 35.33 while that for Weighted/Equivalent Units are 34.67 and 27.12 respectively. The implication is that Consultants rated Start-Finish higher than Contractors, while Contractors also employ the Weighted Milestone method frequently than Consultants. The Contractors also greatly favor the use of Time Ratio method than the Consultants as can be gathered from the mean ranks of 40.14 and 19.54 respectively.

These positions have been collaborated in Table 4, which shows actual results of the non-parametric rank-ordered test statistics. The exact significance levels are entered in the last column under the "Asymptotic Significance". The Z-score states the number of standard deviations above or below the mean score and is a measure of "effect size". Cost Ratio has the highest Mann-Whitney U value of 455, followed by Start-finish (368.5), then Weighted/Equivalent Units (354). The least Mann-Whitney $U$ value of 157 is associated with Time Ratio. Since a bigger Mann Whitney $U$ value implies a smaller difference between the groups, it follows that there is little difference between Contractors' and Consultants' weighting of Cost Ratio method. Inversely, the smaller Mann Whitney $U$ value for Time Ratio method means that the two groups differ greatly in their assessment. 
Table 3. Construction project progress methods-ranks.

\begin{tabular}{|c|c|c|c|c|}
\hline Method & Category of Respondents & $\mathbf{N}$ & Mean Rank & Sum of Ranks \\
\hline & Contractors & 36 & 35.58 & 1281 \\
\hline \multirow[t]{3}{*}{ Units Completed } & Consultants & 26 & 25.85 & 672 \\
\hline & Total & 62 & & \\
\hline & Contractors & 36 & 23.42 & 843 \\
\hline \multirow[t]{3}{*}{ Incremental Milestone } & Consultants & 26 & 42.69 & 1110 \\
\hline & Total & 62 & & \\
\hline & Contractors & 36 & 28.74 & 1034.5 \\
\hline \multirow[t]{3}{*}{ Start-Finish } & Consultants & 26 & 35.33 & 918.5 \\
\hline & Total & 62 & & \\
\hline & Contractors & 36 & 37.86 & 1363 \\
\hline \multirow[t]{3}{*}{ Supervisor's Opinion } & Consultants & 26 & 22.69 & 590 \\
\hline & Total & 62 & & \\
\hline & Contractors & 36 & 31.86 & 1147 \\
\hline \multirow[t]{3}{*}{ Cost Ratio } & Consultants & 26 & 31 & 806 \\
\hline & Total & 62 & & \\
\hline & Contractors & 36 & 40.14 & 1445 \\
\hline \multirow[t]{3}{*}{ Time Ratio } & Consultants & 26 & 19.54 & 508 \\
\hline & Total & 62 & & \\
\hline & Contractors & 36 & 27.67 & 996 \\
\hline \multirow[t]{3}{*}{ Earned Value Analysis } & Consultants & 26 & 36.81 & 957 \\
\hline & Total & 62 & & \\
\hline & Contractors & 36 & 34.67 & 1248 \\
\hline \multirow[t]{2}{*}{$\begin{array}{l}\text { Weighted/Equivalent } \\
\text { Units Completed }\end{array}$} & Consultants & 26 & 27.12 & 705 \\
\hline & Total & 62 & & \\
\hline
\end{tabular}

Table 4. Construction project progress methods-test statistics.

\begin{tabular}{ccccc}
\hline Method & Mann-Whitney U Wilcoxon W & $\mathrm{Z}$ & $\begin{array}{c}\text { Asymptotic } \\
\text { Significance (2-tailed) }\end{array}$ \\
\hline Units Completed & 321 & 672 & -2.251 & 0.024 \\
Incremental Milestone & 177 & 843 & -4.334 & 0.000 \\
Start-Finish & 368.5 & 1034.5 & -1.459 & 0.145 \\
Supervisor's Opinion & 239 & 590 & -4.168 & 0.000 \\
Cost Ratio & 455 & 806 & -0.362 & 0.718 \\
Time Ratio & 157 & 508 & -4.597 & 0.000 \\
Eared Value Analysis & 330 & 996 & -2.227 & 0.026 \\
Weighted/Equivalent Units & 354 & 705 & -1.847 & 0.065 \\
\hline
\end{tabular}

a. Grouping Variable: Category of respondents (Contractors and Consultants). 
The association between the two variables (contractors and consultants) is statistically significant if asymptotic significance ( 2 sides) is less than 0.05 (for a 95\% confidence level). It can be deduced from Table 4 that there is no significant difference in the ratings by the two groups in Cost Ratio and Start-finish methods. As the likelihood that the Contractors and Consultants rated the Cost Ratio method identically is $72 \%$ and that of Start-Finish is $15 \%(0.718>0.05$ and $0.145>0.05)$. The ratings of the other six factors by the two groups are significant $(p<0.05)$. Contractors and Consultants rate them at different rates. For example, the likelihood that the two groups rate the Units completed and Weighted/Equivalent Units methods are 2.4\% and 6.5\%.

\section{Discussion}

The Cost Ratio method was ranked premium of the eight common project progress measurement methods (Table 2). This method relies on the ratio of the actual cost to the estimated cost at completion, to estimate the progress level. As evident in the high Mann-Whitney $U$ value (455) and asymptotic significance of 0.718 (Table 4), both Contractors and Consultants agreed on the method as the most frequent for progress measurement. The popularity of the method can be ascribed to its objectivity, simplicity and speed. The same cost data use in preparing interim certificates by Quantity Surveyors and Project Managers are also relied upon for the progress measurement. Dependence on cost for progress measurement can be misleading in some instances. Project cost is not consistently proportional to duration. For instance, the cost of a minor or small component may be astronomical but its impact on time and quality of work may be negligible. Other contractor pricing strategies such as front or back loading, could distort progress and actual work undertaken. Cost Ratio method becomes aberrant when claims like interest on delayed payments and fluctuations are captured for progress computation. Supervisor's Opinion method (RII of 90.3 and Mean of 4.52) was ranked second by the professionals. The relatively moderate Mann-Whitney $U$ value of 239 can be taken as a degree of difference in the ratings of the two groups. While the Contractors' mean rank was 37.86, the Consultants' had a low mean rank of 22.69. The former group relies on this method frequently than the latter. The overall high ranking of this method is rather surprising because it is rooted in the subjective judgement and anchored in the experience and opinion of supervisors. A plausible explanation could be its fastness and ease of application, coupled with the relatively simple projects involved, endeared this method to the professionals.

The Units Completed, Time ratio and Incremental Milestone methods were ranked from third to fifth. A minor difference between the ratings of the groups in relation to the Units Completed method, as evident in the high Mann-Whitney $U$ value of 321 and the close mean ranks of 35.58 and 25.85, means the contractors have just a slight preference. There are great differences in the responses of the 2 groups to the other two methods. Contractors apply the Time Ratio fre- 
quently than the Consultants and the reverse holds for the Incremental Milestone. Units Completed method is simple and objective for activity level measurement but concentrates on the quantity at the expense of cost and time. The Time Ratio also has limitations similar to the Cost Ratio. It is affected by inclement weather and extension of time thereby altering the actual duration and cost of an activity. The Start-Finish and Weighted/Equivalent Units methods, were lowly ranked, implying they are not commonly used. Their high Mann-Whitney $U$ values are indicative that both groups rated them relatively alike. Their low rankings can partly be explained as unfamiliarity of practitioners with these techniques. Finally, with a mean score of only 1.6 and RII of 31.9, the Earned Value Analysis is the least method used by the construction professionals in assessing project progress. The high value of 330 for the Mann-Whitney $U$, coupled with the close mean ranks of 27.67 and 36.81 shows that both Contractors and Consultants agreed to rarely employ the method. It is unexpected that such an objective technique which gives early indications on project performance should be least appreciated by Ghanaian construction professionals. Probable negative perceptions affecting this method are the large scope of data required and unacquaintance of professionals.

\section{Conclusions}

Eight project progress measurement techniques practised in the Construction Industry of Ghana were identified and tested to determine their frequency and consistency of use. These methods were sourced from literature and ranked by RII and non-parametric Mann-Whitney $U$ test statistics. The Cost Ratio method of construction progress measurement is the preferred choice of construction professionals in Ghana. This system involves the assessment of the actual cost of work executed as a percentage of the total budgeted cost. Its popularity can be attributable to its quick and simple applicability but could be misleading in instances where the cost incurred does not match time or quality of work. The next two favourite methods are Supervisor's Opinion, and Units Completed. Contractors slightly rated them higher than the Consultants but the high ranking of Supervisor's Opinion, in particular, suggest that subjectivity is rooted in progress measurement. Reliability and limitations of such subjective methods which do not integrate all key performance/progress indicators (cost, time and work scope) into the measurement are not the focus of this paper. Current work is about predominant project measurement methods of construction professionals. Time Ratio, Incremental Milestone and Start-Finish ranked between fourth and sixth. Contractors proportionately use the Time Ratio more than the Consultants possible due to its simplicity but delays and even fast pace work delivery can make the system unreliable. Consultants rated Incremental Milestone higher than consultants but both had a level of consensus on the Start-Finish method. These methods are also subjective and rely on the experience of the project manager. Weighted/Equivalent Units was the penultimately ranked ahead of 
Earned Value Analysis. Their low rankings suggest the unfamiliarity of construction professionals but not necessary undependability of the methods. In fact, the lowest ranked is the only technique which factors time, cost as well as quantity of work into the measurement.

This work identified and ranked the common construction project progress measurement methods. Merits of the methods, the critical factors that drive the process of progress measurement and critical barriers militating against a realistic assessment of construction progress will be considered in future studies. The scope was limited to conventional methods which are contingent upon computer-assisted tool formats of 2-dimensioned drawings, bar charts, schedules and photo logs, critical path network and reports. Contemporary progress measuring methods of 3D/4D models with automatic data collection and visualization and real-time presentation of results (such as LADAR, RFID, GPS and Video and Audio technologies) have not been covered in this study.

\section{Acknowledgements}

The authors are grateful to the Ghana Institution of Surveyors (GhIS) and the Association of Building and Civil Engineering Contractors of Ghana (ABCECG) for facilitating the data collection for this paper.

\section{Conflicts of Interest}

The authors declare no conflicts of interest regarding the publication of this paper.

\section{References}

[1] Jung, Y. and Lee, S. (2010) Automated Progress Measurement and Management in Construction: Variables for Theory and Implementation. Nottingham University Press, Nottingham.

[2] Bae, S. (1989) A Study on Improving Progress Management of Construction Work. Department of Construction and Engineering, Chung-Ang University, Korea.

[3] Garold, D.O. (2000) Project Management for Engineering and Construction. 2nd Edition, McGraw Hill, International Edition, Singapore.

[4] Mubarak, S. (2010) Construction Project Scheduling and Control. 2nd Edition, John Wiley \& Sons Inc., Hoboken, NJ. https://doi.org/10.1002/9780470912171

[5] Jung, Y. and Kang, S. (2007) Knowledge-Based Standard Progress Measurement for Integrated Cost and Schedule Performance Control. Journal of Construction Engineering and Management, 133, 10-21. https://doi.org/10.1061/(ASCE)0733-9364(2007)133:1(10)

[6] AACE International (2019) Cost Engineering Terminology. TCM Framework: General Reference. AACE International Recommended Practice No. 10S-90. http://www.aacei.org/docs/default-source/rps/10s-90.pdf?sfvrsn=42

[7] Golparvar-Fard, M., Pena-Mora, F. and Savarese, S. (2009) Application of D AR A 4-Dimensional Augmented Reality Model for Automating Construction Progress Monitoring Data Collection, Processing and Communication. Journal of Information Technology in Construction, 14, 129-153. http://www.itcon.org/2009/13 
[8] Zhang, X., Bakis, N., Lukins, T.C., Ibrahim, Y.M., Wu, S., Kagioglou, M., Aouada, G., Kaka, A.P. and Trucco, E. (2009) Automating Progress Measurement of Construction Projects. Automation in Construction, 18, 294-301.

https://doi.org/10.1016/j.autcon.2008.09.004

[9] Rahimian, F.P., Seyedzadeh, S., Oliver, S., Rodriguez, S. and Dawood, N. (2020) On-Demand Monitoring of Construction Projects through a Game-Like Hybrid Application of BIM and Machine Learning. Automation in Construction, 110, 103012. https://doi.org/10.1016/j.autcon.2019.103012

[10] Amos, S.J. (2004) Skills and Knowledge of Cost Engineering. 5th Edition, AACE International, AACE Education Fund, Morgantown, WV.

https://www.academia.edu/33659523/Skills_and_knowledge_of_cost_engineering

[11] CII-Construction Industry Institute (1987) Project Control for Construction. Bureau of Engineering Research. The University of Texas at Austin Publication No. 6-5.

http://citeseerx.ist.psu.edu/viewdoc/download?doi=10.1.1.22.644\&rep=rep1\&type= pdf

[12] Fleming, Q.W. and Koppelman, J.M. (2000) Earned Value Project Management. 2nd Edition, Project Management Institute, Newtown Square, PA.

[13] Mubarak, S. (2010) Construction Project Scheduling and Control. 2nd Edition, John Wiley \& Sons Inc., Hoboken, NJ. https://doi.org/10.1002/9780470912171

[14] Thomas, H.R. and Mathews, C.T. (1996) An Analysis of the Methods of Measuring Construction Productivity. Construction Industry Institute. Bureau of Engineering Research, University of Texas, Austin, TX.

[15] Chin, S., Yoon, S., Kim, Y.-S., Jung, Y., Park, S.-C. and Chung, M. (2006) A Project Progress Measurement and Management System. Journal of Construction Engineering and Management, 132, No. 4. https://www.irbnet.de/daten/iconda/CIB13684.pdf

[16] Jung, M., Ko, S. and Chi, S. (2017) A Progress Measurement Framework for Large-Scale Urban Construction Projects. KSCE Journal of Civil Engineering, 22, 2188-2194. https://link.springer.com/article/10.1007/s12205-017-0245-2 https://doi.org/10.1007/s12205-017-0245-2

[17] Chau, K.W., Anson, M. and Zhang, J.P. (2005) 4D Dynamic Construction Management and Visualization Software: 1. Development. Automation in Construction, 14, 512-524. https://doi.org/10.1016/j.autcon.2004.11.002

[18] El-Omari, S. and Moselhi, O. (2009) Integrating Automated Data Acquisition Technology for Progress Reporting of Construction Project. 26th Edition, ISARC, Canada. https://doi.org/10.22260/ISARC2009/0048

[19] Navon, R. (2007) Research in Automated Measurement of Project Performance Indicators. Automation in Construction, 16, 176-188.

https://www.sciencedirect.com/science/article/abs/pii/S0926580506000136 https://doi.org/10.1016/j.autcon.2006.03.003

[20] AACE International (2015) Total Cost Management (TCM) Framework: An Integrated Approach to Project, Program, and Portfolio Management. 2nd Edition. https://www.aacei.org/tcm

[21] AACE International (2007) Skills and Knowledge of Cost Engineering. 5th Edition, AACE Education Fund, Morgantown, WV.

[22] Eldin, N.N. (1989) Measurement of Work Progress: Quantitative Technique. Journal of Construction Engineering and Management, 115, 462-474. https://doi.org/10.1061/(ASCE)0733-9364(1989)115:3(462) 
[23] Bower, D.C. (2007) New Directions in Project Performance and Progress Evaluation. Property and Project Management, RMIT University, Melbourne, Australia. https://researchbank.rmit.edu.au/eserv/rmit:6332/Bower.pdf

[24] Aliverdi, R., Naeni, L.M. and Salehipour, A. (2013) Monitoring Project Duration and Cost in a Construction Project by Applying Statistical Quality Control Charts. International Journal of Project Management, 31, 411-423. https://doi.org/10.1016/j.ijproman.2012.08.005

[25] Bayrak, T. (2008) Semi-Automatic Construction Progress Measurement Using a Combination of CAD Modelling, Photogrammetry and Construction Knowledge. A $\mathrm{PhD}$. thesis submitted to the School of The Built Environment, Heriot-Watt University, Edinburgh, Scotland.

[26] Vandevoorde, S. and Vanhoucke, M. (2006) A Comparison of Different Project Duration Forecasting Methods Using Earned Value Metrics. International Journal of Project Management, 24, 289-302. https://doi.org/10.1016/j.ijproman.2005.10.004

[27] Czemplik, A. (2014) Application of Earned Value Method to Progress Control of Construction Projects. XXIII R-S-P Seminar, Theoretical Foundation of Civil Engineering (23RSP). Procedia Engineering, 91, 424-428.

https://doi.org/10.1016/j.proeng.2014.12.087

[28] PMI (2005) Practice Standard for Earned Value Management. Management Institute, Newtown Square, Newtown Square, Pennsylvania, PA.

[29] Art Gowan, J., Mathieu, R.G. and Hey, M.B. (2006) Earned Value Management in a Data Warehouse Project. Information Management and Computer Security, 14, 37-50. https://doi.org/10.1108/09685220610648364

[30] Cioffi, D.F. (2006) Designing Project Management: A Scientific Notation and an Improved Formalism for Earned Value Calculations. International Journal of Project Management, 24, 136-144. https://doi.org/10.1016/j.ijproman.2005.07.003

[31] Saunders, M., Lewis, P. and Thornhill, A. (2009) Research Methods for Business Students. 5th Edition, Pearson Education Limited, Harlow.

[32] Sekaran, U. and Bougie, R. (2016) Research Methods for Business: A Skill Building Approach. 7th Edition, John Wiley and Sons, New York.

[33] Denscombe, M. (2010) The Good Research Guide for Small-Scale Social Research Projects. 4th Edition, Open University Press, McGraw-Hill, Berkshire.

[34] Enshassi, A., Sherif, M., Ziad, A.M. and Peter, E.M. (2007) Factors Affecting Labour Productivity in Building Projects in the Gaza Strip. Journal of Civil Engineering and Management, 13, 245-254. https://doi.org/10.3846/13923730.2007.9636444

[35] Antwi, A.Y. (2000) Urban Land Markets in Sub-Saharan Africa: A Quantitative Study of Accra, Ghana. Napier University, Edinburgh, UK.

[36] Ahadzie, D.K. (2007) A Model for Predicting the Performance of Project Managers in Mass House Building Projects in Ghana. University of Wolverhampton, Wolverhampton, UK.

[37] Dancey, C. P. and Reidy, J. (2011) Statistics without Maths for Psychology: Using SPSS for Windows. 4th Edition, Pearson Education Limited, Prentice Hall, Harlow.

[38] Arthur, A., Elliot J.C. and Elaine, N.A. (2013) Statistics for Psychology. Sixth Edition, Pearson Education Limited, Upper Saddle River, NJ. 